Being the proceedings of a conference this book displays the characteristics of the species. On one hand, no concessions are made to those unfamiliar with the jargon of the subject and the book could not serve as an introductory text. On the other hand, it provides a stimulating insight into future possibilities for those with some background in the subject. However, perhaps some prospective buyers may be put off by these introductory comments by Mitchison and Merrick.

"We wondered whether to conclude with some advice on how to get rich. This section would have been aimed at stockbrokers thinking of investing money in biotechnology companies, and would have told them just which products of the human immune system are worth cloning, what would be the likely size of the market, and where the competition stands at present. But on second thoughts we have decided to remain silent on the grounds that such advice, if unpaid, is seldom listened to."

N Matthews

The Harvey Lectures Series 78 (1982-1983)

(Pp 270; figures + tables. £34·00.) Florida: Academic Press. 1984.

Every winter since 1905 on the third Thursday of the month the Harvey Society of New York has met to hear a lecture on a biomedical topic. To be invited to lecture is a high distinction, and the list of Harvey lecturers is a roll call of the great and the good. The present volume contains nine lectures delivered between September 1982 and May 1983; at least the title page promises nine lectures but the book only contains eight because one manuscript was not received in time.

In book form the lectures face two problems, the publication delay and the wide range of topics included. The exceptionally wide range, far wider than in the usual multi-author review volume, follows from the wide interests of the Harvey Society. Eighty years ago perhaps this was no problem, but today how many people can really appreciate lectures on both 'Control of Intercellular Communication by way of Gap Junctions' (30 pages of voltage gating) and 'Left-handed Z-DNA'? This is breadth without unity.

The most obvious casualty of publication delay is J Michael Bishop's 'Viruses, Genes and Cancer'. He sees oncogenes as "the enemy within" and the text is full of metaphors of attack and subversion. It must have been an entertaining performance in March 1983 , but has been badly overtaken by later dis- coveries. Ruth Sager's lecture on 'Chromosome Modification and Cancer' has aged better. After her discovery of chloroplast DNA she showed that the maternal transmission depends on methylation (unmethylated paternal chloroplast DNA is degraded). This led to studies of methylation in a mammalian cell line. The methylation inhibitor azacytidine produced cells which had become tumorigenic, but which also had a consistent chromosome abnormality. This lecture still reads well two years later because she avoids a general review and just describes the excellent work of her own group. Other lectures similarly record one group's progress in a straight line across an uncharted area and these too make good reading. Alexander Rich's chapter on 'Left-handed Z-DNA' shows the steady development from the early studies of dinucleotide crystals to possible Z-DNA sequences generated by supercoiling and transcriptional enhancers. It left me feeling I understood the topic for the first time.

With speakers who have made such large personal contributions to their subjects, many of the lectures have an autobiographical tone and it is this feature which makes the most enjoyable reading: "One can imagine the excitement when in the afternoon of December 24 1962, Ed noticed a strikingly abnormah electrophoretic pattern in the serum and urine of nes less a man than Bellevue hospital employee. . within 3 days the protein had been defined as molecule with many properties of an Fc fragment and an abstract was submitted to the FASEB". This comes from a review of the heavy chain diseases read by the widow and co-worker of the late Edward C Franklin.

The original lectures must have been a real intellectual feast, but I don't feel they make a particularly satisfactory book. It is pleasantly produced on good glossy paper, and the photographs are printed well (though I did notice a couple of misplaced captions). You would certainly buy it if you were interested in following the work of a particular group - and much of the work described is historically important-but for general reviews of a field you would usually do better with something less personal and more up to date.

ANDREW P ReAD

\section{Genetics and Neurology}

By Sarah Bundey. (Pp 340; figures + tables. £28.00.) Edinburgh: Churchill Livingstone. 1985.

This book is "meant to provide practical information regarding clinical delineation of different entities, their genetic mechanisms, and the recurrence 